\title{
Social Nervous Exercise Intervention and Its Association with Fasting Blood Glucose on Diabetes Mellitus Gestational
}

\author{
Effatul Afifah ${ }^{1,2 *}(\mathbb{D})$, Detty Siti Nurdiati ${ }^{3}$ D, Hamam Hadi $^{1}$ (D), Zaenal Muttaqien Sofro ${ }^{4}$, Ahmad Hamim Sadewa ${ }^{5}$ \\ ${ }^{1}$ Department of Nutrition, Faculty of Health Sciences, Alma Ata University, Yogyakarta, Indonesia; ${ }^{2}$ Department of Medicine and \\ Health Science, Faculty of Medicine, Public Health and Nursing, Universitas Gadjah Mada, Yogyakarta, Indonesia; ${ }^{3}$ Department \\ of Obstetrics and Gynecology, Faculty of Medical Science Publich Health and Nursing, Gadjah Mada University, Yogyakarta, \\ Indonesia; ${ }^{4}$ Department of Physiology, Faculty of Medical Science Publich Health and Nursing, Gadjah Mada University, \\ Yogyakarta, Indonesia; ${ }^{5}$ Department of Biochemistry, Faculty of Medical Science Publich Health and Nursing, Gadjah Mada \\ University, Yogyakarta, Indonesia
}

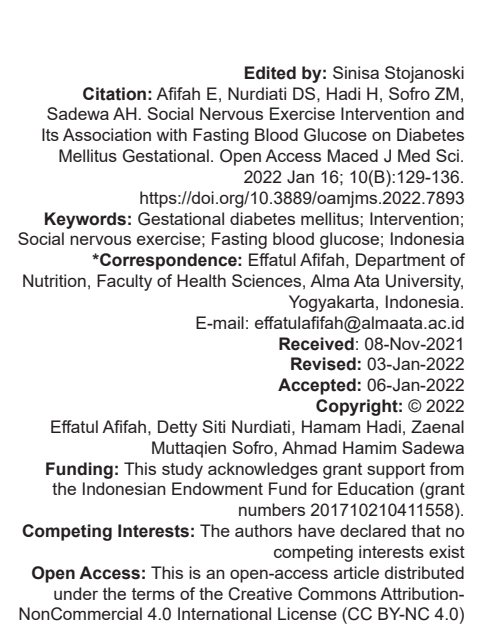

Abstract

BACKGROUND: Gestational diabetes mellitus (GDM) has been identified as a major complication of pregnancies and has remained a major cause of perinatal morbidity and mortality, in both mother and child. Exercise can be used as a strategy to reduce hyperglycemia experienced during GDM. Regular exercise is important for a healthy pregnancy and can lower the risk of developing GDM. For women with GDM. Exercise is safe and can affect the pregnancy outcomes beneficially. The role of exercise about increases skeletal muscle glucose uptake and minimizing hyperglycemia. Social nervous (SaSo) exercise is a moderate-intensity exercise intervention that plays a role in controlling blood glucose through autonomic nervous stimulation so that it has an effect on glucose homeostasis. Social nervous exercise can stimulate the parasympathetic or myelinated vagus nerves. The socia nerve or the social nervous system is the vagus nerve nc-X which is supported by cranial nerves, namely, nerves $\mathrm{V}$, VII, IX, and XI centered in the nucleus ambiguous.

AIM: The aim of the study is to determine the impact of a social nervous (SaSo) exercise training program consisting of warm-up, core (prayer movements), and cooling exercises on glucose homeostasis parameters in pregnant women diagnosed with GDM

METHODS: Thirty-seven pregnant women diagnosed with GDM at 24-28 weeks of gestation were allocated into two groups, thats the experimental group $(n=19)$ with the SaSo program being regularly monitored and the contro group $(n=18)$ receiving only standard antenatal care for GDM. The Saso program started from the time diabetes was diagnosed until 6 weeks of intervention. Interventions were performed twice per week and sessions lasted $40-45 \mathrm{~min}$.

RESULTS: The baseline results for the experimental and control groups were homogeneous, without differences in the baseline variables $(p>0.05)$. Social nervous exercise the experimental group significantly reduced fasting blood glucose levels $(p<0.001)$ compared to the control group.

CONCLUSIONS: A social nervous exercise program has a beneficial effect on fasting blood glucose levels in late pregnancy.

\section{Introduction}

Gestational diabetes mellitus (GDM) is identified as a major complication of pregnancy and a major cause of perinatal morbidity and mortality, in both mother and child [1]. The WHO in 2016, the prevalence of DMG worldwide ranged from $7 \%$ to $11.6 \%$ with a higher incidence occurring in Asian and Pacific Islander descent, and the incidence increased along with increasing cases of obesity. According to the 2017 IADPSG, the prevalence of GDM worldwide ranges from $6.6 \%$ to $45.3 \%$. Recognized risk factors for developing GDM include physical inactivity, being overweight or obese, excessive weight gain during pregnancy, family history of type 2 diabetes mellitus, high parity, and advanced maternal age [2].
GDM and hyperglycemia in pregnancy is caused by several increased hormones produced by the placenta, one of which is human placental lactogen, this hormone causes insulin resistance. Insulin resistance is one of the many physiological changes that occur during pregnancy. This insulin resistance condition continues to increase with gestational age and will persist at the $24^{\text {th }}$ week. As long as the mother's pancreas can continue to produce and secrete adequate amounts of insulin, hyperglycemia can be prevented [3]

Managing physical activity is needed in the body's metabolic processes. When a person does physical activity, there will be muscle contractions which in turn will make it easier for glucose to enter the cells. Physical activity will reduce insulin resistance and so will reduce blood sugar levels [4]. Exercise can be used as a strategy to reduce hyperglycemia and insulin resistance in GDM. To date, 
observational studies have shown that exercise can be a non-invasive therapeutic option to prevent and manage GDM that can be applied to the antenatal population [5]. Regular exercise increases muscle glucose uptake, mitochondrial biogenesis, increases oxidative capacity, improves insulin sensitivity and vascular function, and reduces systemic inflammation [2].

In addition to exercise, many non-invasive therapies have emerged for diabetes mellitus. Recently, found a medical treatment by stimulating the nerves of the brain and specific innervation, including the parasympathetic, sympathetic, sensory and enteric nervous systems. Bioelectronic medicine uses electrical stimulation to modulate the activity of peripheral nerves [6]. In particular, the brain acts through peripheral innervation to different organs and has an important role in maintaining glucose homeostasis. Evidence for this important glucose regulatory mechanism comes from the work of the physiologist Claude Bernard who first demonstrated a causal relationship between cerebral stimulation of the fourth ventricle in the brain and plasma glucose levels [7]. It is therefore not surprising that recent research in the field of diabetes has explored the neural mechanisms involved in glucose control [7], [8].

The autonomic nervous system consists of parasympathetic nerves and sympathetic nerves. The sympathetic nervous system (SNS) is recognized for its role in cardiovascular and metabolic control. In the pancreas, SNS activation is associated with decreased insulin and increased glucagon levels in the portal circulation and in peripheral tissues such as skeletal muscle and adipose tissue. Individuals with diabetes mellitus, hypertension, and dyslipidemia experience increased sympathetic nerve activity [9], [10]. Increased sympathetic activity in healthy adults leads to insulin resistance, mainly through reduced blood flow [7].

The increase in sympathetic nerves in individuals needs to be inhibited by increasing parasympathetic nerve activity so that there will be a balance in the autonomic nerves [11]. According to the Polyvagal theory, the myelinated parasympathetic nerves (V, VII, IX, X, and XI) play a role in social communication, which function to calm oneself and inhibit the influence of the adrenal-sympathetic and hypothalamic-pituitary-adrenal axis. Parasympathetic nerve stimulation will reduce sympathetic nerve activation [12]. Parasympathetic nerve stimulation can stimulate the pancreas and insulin through stimulation of acetylcholine receptors [13]. Based on the findings of Porges [14], [15], [16], the researchers developed a set of exercises that can stimulate the parasympathetic nerves and can inhibit sympathetic nerve activity. As a result, these barriers can increase glucose homeostasis, so that it is expected to decrease blood glucose.

The purpose of this study was to analyze the effectiveness of the social nervous exercise intervention (SaSo) on fasting blood glucose and analyze data on sociodemographic characteristics, food intake, physical activity, pregnancy body mass index (BMI), health conditions of pregnant women, and pregnancy history in women with DMG in Yogyakarta, Indonesia.

\section{Methods}

\section{Selection and description of partisipans}

The subjects of this study were 19 respondents in the intervention group and 18 respondents in the control group. Purposive sampling was done in collecting the research data. Inclusion criteria included pregnant women who had a pregnancy check-up at 24-28 weeks of gestation by examining GDP and OGTT, pregnant women diagnosed with DMG with a GDP value of $92 \mathrm{mg} / \mathrm{dL}$ followed by OGTT $\geq 140$, pregnant women who had never had diabetes before pregnancy and were diagnosed diabetes mellitus for the $1^{\text {st }}$ time in pregnancy, willing to be a research respondent stated by filling out an informed consent form, and Muslim faith. Exclusion criteria included: Contraindications to exercise for more than $30-45$ min performed more than 2 times/week, pregnant women following other exercise programs, pregnant women with heart disease, or chronic kidney disease, medications that affect glucose tolerance (drug administration), which affect blood glucose levels such as Glibenclamide, metformin and other drugs in the treatment of diabetes), and multiple pregnancies.

\section{Technical information}

This study using a quasi-experimental design with pre-test and post-test control group which was conducted in October 2019-April 2020. Two primary health-care centers in Bantul DIY, namely, Banguntapan 2 and Sewon 2 were chosen to be the locations of this study based on the prevalence of women with GDM in the 2019 study. This research was conducted in two stages; the first stage of research was done with the survey method by conducting a screening test to detect women with GDM. This screening was done by checking fasting blood glucose in pregnant women after fasting for 8-10 h, and then followed by an OGTT blood glucose test. Based on the calculation of the sample, 20 women with DMG were needed, plus $10 \%$ of the anticipated loss of pregnant women in each group.

The second stage of the study was to conduct an experimental research design, namely, a quasiexperimental with pre-test and post-test control group aimed at evaluating the intervention by analyzing the causes and effects of the intervention on the research outcomes, but not using randomization. Randomization was not possible due to health ethics reasons, where all the women with DMG had the right to participate in social nervous exercise interventions because they experienced an increase in blood glucose. At the 
beginning of the study, the researcher explained the aims, objectives, positive and negative impacts of the intervention, and determined those with willingness to participate in the intervention. The SaSo also had its own subject criteria according to the guidelines and all samples had the same opportunity to be included in the intervention group and control group.

The research instruments used were as follows: The basic characteristic questionnaire of the respondents included: Age, education level, type of occupation, family history of DM, parity, impaired glucose tolerance, and history of babies born with birth weight $>4000 \mathrm{~g}$. The respondent's anthropometric and clinical data questionnaire included: Current weight, TB status, BMI, and blood pressure. The Semi Quantitative Food Frequency Questionnaire and a food photo book standard Riskesdas (2013) were used to estimate the food intake consumed by the pregnant women with an in-depth interview guide. ACCU check (Performa) (Roche Diabetes Care GmbH 68305 Mannheim Germany) was used for checking fasting blood sugar levels at the time of screening for DMG. Blood collection used venous blood, while the enzymatic glucose measurement used the GOD-PAP method derived from venous blood measured before and after the exercise intervention. The International Physical Activity Questionnaire was used regarding the type and duration of physical activity. Measuring height (Microtoise) and weight used a stepping scale (OneMed) and a sports video was shown as a guide for exercise implementation for the mothers with DMG.

The experimental group had the intervention with structured SaSo exercises twice per week along with standard prenatal care. The exercise program began 1 week after the diagnosis of GDM and was continued for up to 6 weeks. Subject attendance was recorded at each training session. The minimum total duration of the SaSo exercise program was set at a minimum of 6 weeks. Minimum attendance was set at $80 \%$. Pregnant women in the control group only received standard care for DMG only.

Each training session lasted 40-45 min. Movement steps in the SaSo consist of several movement sessions, including: 1) Warm-up movements, for 5-10 $\mathrm{min}$, are done in a sitting and lying position. The warm-up session consists of stretching the pelvic muscles, back, and a combination of yoga movements with breathing settings, accompanied by an ambient musical instrument, namely, Kitaro music and 2) core movements accompanied by instrumental music, core exercises (20-25 $\mathrm{min}$ ) that include: The first core movement is a complete prayer movement, which is a movement of posture, gestures, and breathing. The second core movement is the repetition of the first core movement which is done 3 times, and the third core movement that includes: Three therapies, namely, 1) listening therapy, this therapy allows pregnant women to listen to the morotal Al-Quran Surah Ar-Rahman by doing the respiratory cycle (deep breath); 2) vocalization therapy is applied by reading the Qur'an (short letters Al-lkhlas, Al-Falaq and An-Nas) repeated 3 times, pregnant women read the Qur'an together with a loud voice; and 3) smile therapy, pregnant women make smiles by involving the heart with musical instruments which makes them happy and smiling accompanied by a song made by a goose or duck, and the last one is a cool-down movement, which is a relaxation period to end the session (10 $\mathrm{min})$. This final movement is performed in a sitting and lying position. The SaSo is a combination of prayer movements with breathing exercises and yoga postures and combines all major muscle groups. During the exercise sessions, the pregnant women are provided with sufficient drinking water to prevent dehydration. The SaSo exercises are done using yoga mats and blocks as a seat for the sitting position.

\section{Ethics approval}

Ethical approval was obtained from the Medical and Health Research Ethics Committee of the Faculty of Medicine, Universitas Gadjah Mada Yogyakarta (KE/0978/08/2019). The subjects in this study had completed an informed consent from before conducting the study. The research process upheld the Helsinki declaration to meet the standards of research conducted with good ethical practices.

\section{Statistical analysis}

All numeric data are presented in the mean with standard deviation and categorical data are presented in frequency $(n)$ and percentage (\%). Univariate analysis was used to analyze the respondents' characteristic data such as age, nutritional status, hypertension status, history of hypertension, parity, family history of DM, history of macrosomia, education, and occupation.

The data normality test was conducted to determine whether the data were normally distributed or not. The normality test of the data was done with the Kolmogorov- Smirnov test for the group with the number of samples $(n>50)$ and the Shapiro-Wilk test for the group with the number of samples $(n<50)$. If $p$ value was significant $(p \geq 0.05)$, then the data were considered normally distributed, and if ( $p \leq 0.05)$, then the data were considered not normally distributed.

Bivariate analysis was used to test the difference in means with pre-test and post-test results in one group using paired sample t-tests. Meanwhile, to test the mean difference with the pre-test and post-test designs between the two groups, namely, the intervention and control groups, if the data were normally distributed then independent sample t-tests were used and the Mann-Whitney test for the data 
not normally distributed. Data analysis used STATA version 13.1 special edition software.

\section{Trial registration}

Ethical approval was obtained from the Medical and Health Research Ethics Committee of the Faculty of Medicine, Gadjah Mada University Yogyakarta (KE/0978/08/2019).

\section{Results}

Screening results obtained 45 women with DMG. The pregnant women were offered whether they were willing to take part in the study and were willing to do exercise as the form of intervention given. A total of 24 pregnant women $(n=24)$ who were willing to participate in the SaSo exercises were included in the intervention group, and there were 21 women with DMG $(n=21)$ not willing to participate in the SaSo exercises who were included in the control group. However, there were eight pregnant women who dropped out during the data collection process so that the number of participants that could be analyzed completely included 19 in the intervention group and 18 in the control group (Figure 1).

\section{Subject characteristics}

The characteristics of the pregnant women are presented in Table 1. Based on age data, the largest percentage of pregnant women were in the not at risk age category with 17 respondents $(89.5 \%)$ in the intervention group and 13 respondents $(72.2 \%)$ in the control group. The maternal nutritional status data indicated most were in the overweight category, namely, 12 respondents $(63.2 \%)$ in the intervention group and 10 respondents $(55.6 \%)$ in the control group. The hypertension status in most of the pregnant women was in the non-hypertensive category, namely, 17 respondents $(89.5 \%)$ in the intervention group and 13 respondents $(72.2 \%)$ in the control group.

The largest history of hypertension data was in the non-hypertensive category, namely, 16 respondents $(84.2 \%)$ in the intervention group, while 17 respondents $(94.4 \%)$ in the control group. The parity data indicated most mothers were in the primipara category, namely, 11 respondents $(57.89 \%)$ in the intervention group, and in the control group, most were in the nullipara category, with 9 respondents $(50.0 \%)$.

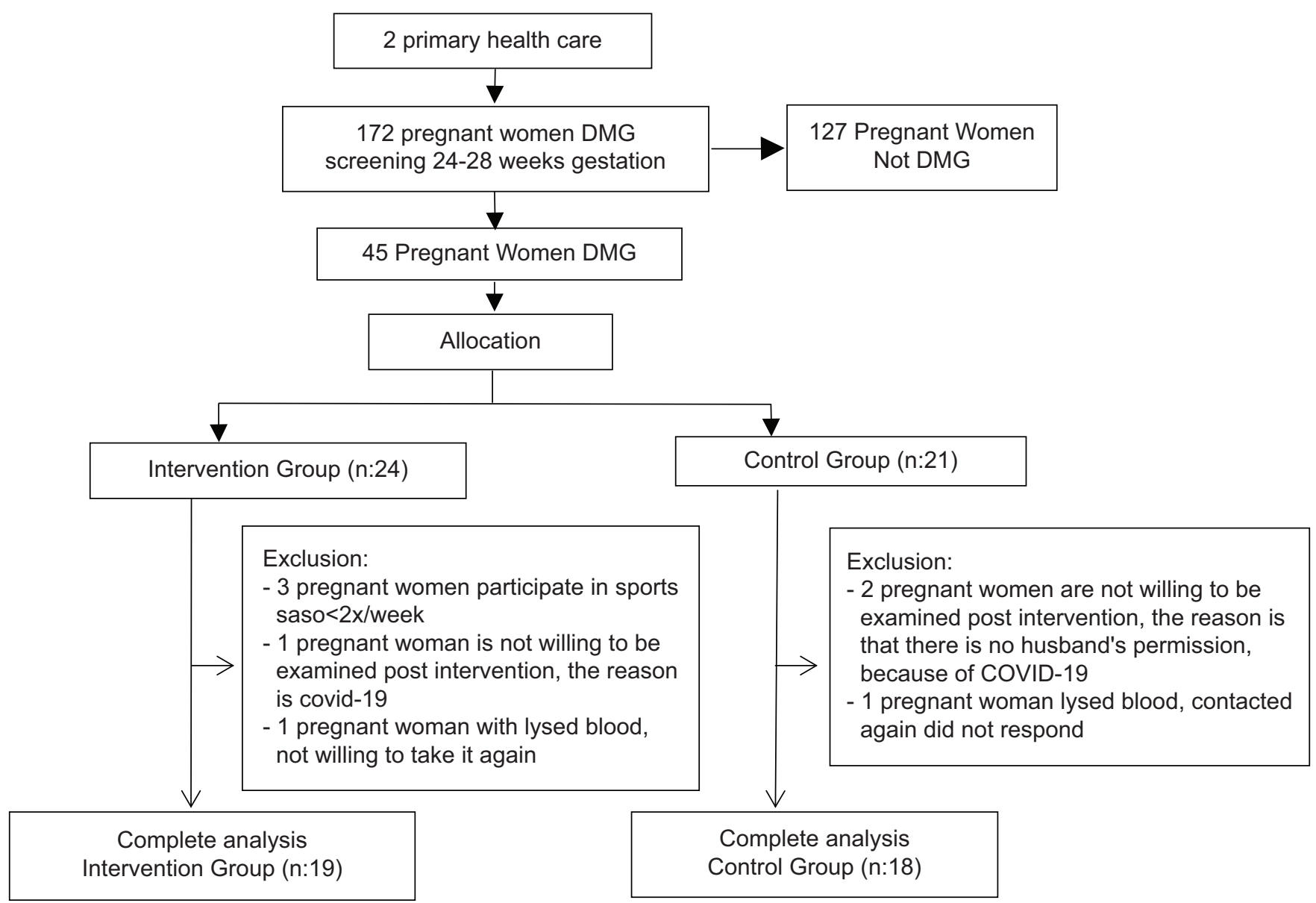

Figure 1: Flowchart of participation in social nervous exercise intervention study 
Table 1: Characteristics of pregnant women in the intervention and control groups

\begin{tabular}{|c|c|c|c|c|c|}
\hline \multirow[t]{3}{*}{ Characteristics of pregnant women } & \multicolumn{4}{|c|}{ Group } & \multirow[t]{3}{*}{$p$ value } \\
\hline & \multicolumn{2}{|c|}{ intervention (19) } & \multicolumn{2}{|c|}{ Control (18) } & \\
\hline & $\mathrm{F}$ & $\%$ & $\mathrm{~F}$ & $\%$ & \\
\hline Age & & & & & 0.734 \\
\hline At Risk $<20$ and $>35$ & 4 & 21.05 & 3 & 16,67 & \\
\hline No Risk 20-35 & 15 & 78,95 & 15 & 83.33 & \\
\hline Nutritional status (BMI) & & & & & 0.486 \\
\hline Underweight & 1 & 5.3 & 0 & 0.0 & \\
\hline Normal & 6 & 31.6 & 8 & 44.4 & \\
\hline Overweight & 12 & 63.2 & 10 & 55.6 & \\
\hline Hypertension Status & & & & & 0.181 \\
\hline Yes & 2 & 10,5 & 5 & 27,8 & \\
\hline No & 17 & 89.5 & 13 & 72.2 & \\
\hline History of Hypertension & & & & & 0.316 \\
\hline Yes & 3 & 15.8 & 1 & 5.6 & \\
\hline No & 16 & 84.2 & 17 & 94.4 & \\
\hline Parity & & & & & 0.332 \\
\hline Nullipara & 5 & 26.32 & 9 & 50.00 & \\
\hline Primipara & 11 & 57.89 & 7 & 38.89 & \\
\hline Multipara & 3 & 15.79 & 2 & 11.11 & \\
\hline Family DM history & & & & & 0.181 \\
\hline Yes & 2 & 10.5 & 5 & 27.8 & \\
\hline No & 17 & 89.5 & 13 & 72.2 & \\
\hline History of macrosomia & & & & & 0.580 \\
\hline Yes & 2 & 10.5 & 1 & 5.6 & \\
\hline No & 17 & 89.5 & 17 & 94.4 & \\
\hline Mother's education & & & & & \\
\hline Primary school & 0 & 0.0 & 1 & 5.6 & 0.309 \\
\hline Junior high school & 0 & 0.0 & 2 & 11.1 & \\
\hline Senior high school & 15 & 8.95 & 11 & 61.1 & \\
\hline College & 4 & 21.1 & 4 & 22.2 & \\
\hline Mother's Job & & & & & \\
\hline Housewife & 14 & 73.7 & 14 & 77.8 & \\
\hline Civil servants/private Civil servants & 4 & 21.1 & 3 & 16.7 & 0.944 \\
\hline Entrepreneur & 1 & 5.26 & 1 & 5.56 & \\
\hline Mother's Job & & & & & \\
\hline Physical activity & & & & & \\
\hline Light & 3 & 15.8 & 3 & 16.7 & 0.942 \\
\hline Currently & 16 & 84.2 & 15 & 83.3 & \\
\hline
\end{tabular}

\section{Changes in average fasting blood glucose levels before and after intervention}

The results of the fasting blood glucose data analysis showed that in the intervention group the mean fasting blood glucose level decreased significantly between before and after the intervention with $p<0.05$. Meanwhile, the control group showed an increase in fasting blood glucose levels $(p>0.05)$ between before and after the intervention, as shown in Table 2.

Table 2: Mean changes in fasting blood glucose levels before and after intervention

\begin{tabular}{|c|c|c|c|c|c|c|c|}
\hline \multirow[t]{2}{*}{ Variable } & \multirow[t]{2}{*}{ Groups } & \multirow[t]{2}{*}{ Observation } & \multirow{2}{*}{$\begin{array}{l}\text { Mean } \pm \text { standard } \\
\text { deviation }\end{array}$} & \multirow[t]{2}{*}{ MD } & \multicolumn{2}{|l|}{$95 \% \mathrm{Cl}$} & \multirow[t]{2}{*}{$\mathrm{p}$ value } \\
\hline & & & & & Lower & Upper & \\
\hline Fasting & Intervention & Pre & $92.63 \pm 6.26$ & -4.42 & -7.17 & -1.66 & $0.003^{*}$ \\
\hline blood & & Post & $88.21 \pm 6.23$ & & & & \\
\hline glucose & Control & Pre & $94.22 \pm 6.12$ & 5.39 & 1.60 & 9.18 & $0.008^{*}$ \\
\hline & & Post & $99.61 \pm 7.20$ & & & & \\
\hline
\end{tabular}

\section{The effect of social nervous exercise on} fasting blood glucose levels

Table 3 shows that the results of the analysis of the mean fasting blood glucose in the intervention group were significantly different from the control group $(p<0.05)$. In the intervention group, there was a decrease in the mean fasting blood glucose, while in the control group the mean fasting blood glucose increased.
Table 3: Relationship between social nervous exercise intervention on fasting blood glucose

\begin{tabular}{|c|c|c|c|c|c|c|}
\hline \multirow[t]{2}{*}{ Variables } & \multirow[t]{2}{*}{ Groups } & \multirow{2}{*}{$\begin{array}{l}\text { Mean } \pm \text { Standard } \\
\text { deviation }\end{array}$} & \multirow[t]{2}{*}{$\Delta$ mean } & \multicolumn{2}{|l|}{$95 \% \mathrm{Cl}$} & \multirow[t]{2}{*}{$p$-value } \\
\hline & & & & Lower & Upper & \\
\hline $\begin{array}{l}\text { Fasting } \\
\text { blood }\end{array}$ & $\begin{array}{l}\text { Intervention (SaSo } \\
\text { exercise) }\end{array}$ & $-4.42 \pm 5.72$ & -9.80 & -14.28 & -5.33 & $0.000^{*}$ \\
\hline glucose & Control & $5.39 \pm 7.62$ & & & & \\
\hline
\end{tabular}

\section{Discussion}

\section{Subject characteristics}

The results of base line data analysis showed that the majority of respondents in the intervention group $(89.5 \%)$ and the control group $(72.2 \%)$ were in the safe age range during pregnancy, namely, the range of 20-35 years. If a woman becomes pregnant at the age of $<20$ years or $>35$ years, then the risk of experiencing complications in pregnancy will be greater. The previous research has shown that women who become pregnant at the age of 35 or $<17$ years have a greater risk of experiencing severe maternal morbidity compared to women who become pregnant at the age of 25-29 years [15]. In this study, the nutritional status of the majority of pregnant women belonged to the overweight category (BMI $>25.0 \mathrm{~kg} / \mathrm{m}^{2}$ ), with $63.2 \%$ in the intervention group and $55.6 \%$ in the control group. The remaining $31.6 \%$ and $44.4 \%$ of respondents had normal nutritional status in the intervention and control groups, while there were only one respondent or $5.3 \%$ in the intervention group and $0 \%$ in the control group with underweight status. Nutritional status during pregnancy is one indicator that can affect pregnancy and pregnancy outcomes. The previous research has shown that underweight and overweight/obese conditions can have an adverse effect on pregnancy [17].

Concerning the hypertension status, $89.5 \%$ of respondents did not experience hypertension in the intervention group while for the control group, it was $72.2 \%$. Most respondents had no history of hypertension, with $84.2 \%$ in the intervention group and $94.4 \%$ in the control group. Some research results explained that the status of hypertension in pregnancy will adversely affect pregnancy. In the United States, chronic hypertension affects $1-5 \%$ of pregnancies and it is known that GDM complicates $1-14 \%$ of pregnancies. Pregnancy can become complicated by hypertension and gestational hypertension is associated with increased maternal mortality and perinatal morbidity. Adverse outcomes associated with hypertension include: Premature birth, caesarean section, fetal growth restriction, perinatal death, preeclampsia, acute renal failure, edema, and stroke or maternal death [16].

The results of parity analysis also showed that about $40-50 \%$ of respondents in the intervention and control groups were in primiparous parity status. Several studies have shown the effect of parity on increasing blood glucose. Fasting plasma glucose 
levels increase with increasing number of live births. Parity status has a significant relationship with GDM. Women who have had two, three, and four or more live births have 1.35 times higher risk, and the risk of diabetes is significantly higher than women who had one live birth [18].

Respondents with a family history of DM were $10-30 \%$. Several studies have stated that there is a significant relationship between a family history of DM and GDM. The prevalence of GDM was significantly associated with a family history of DM [19], [20], [21], [22], [23], [24]. Family history of DM has a significant association with the risk of macrosomia and cesarean delivery during pregnancy [22]. Research data showed that there is a history of macrosomia in about $5.6-10.5 \%$ of respondents who have a history of giving birth to a macrosomic baby in a previous pregnancy. An overview of education and employment data indicated an average of $60-80 \%$ of respondents with a high school education or equivalent (SMA), and $20 \%$ who have a high education. As many as $70-80 \%$ of respondents work as housewives and the rest are civil servants and entrepreneurs. Respondents with this level of education will have a sufficient level of awareness and knowledge to accept interventions and education provided to improve health status of pregnant women.

\section{Effects of social nervous exercise on fasting blood glucose}

Patients with hypertension and dyslipidemia have increased sympathetic nerve activity [9]. Flaa et al. [23] concluded that sympathetic activity precedes prediabetes and the development of insulin resistance. Increased sympathetic activity in healthy adults leads to insulin resistance, mainly through reduced blood flow. The increase in sympathetic nerves needs to be inhibited by increasing parasympathetic nerve activity so that there will be a balance in the autonomic nerves [11]. One way to increase the activity of the parasympathetic nervous system is to do SaSo exercise, which are exercise movements that aim to stimulate the parasympathetic nerves by inhibiting sympathetic nerve activity in achieving glucose homeostasis. The SaSo exercise involves low-intensity movements exercising the autonomic nerves that regulate balance in the body. The SaSo exercises can stimulate the myelinated parasympathetic nerve (vagus nerve/X) which is supported by the V, VII, IX, and XI cranial nerves. These are collectively referred to as the social nerves, namely, the nerves: V, VII, IX, X, and XI, which are connected through the corticobulbaris pathways [11]

Table 3 shows that social nervous exercise can reduce insulin resistance levels, possibly through two mechanisms: (1) Stimulation of the parasympathetic nervous system as a social nerve consisting of nc $V$, VII, IX, X, and XI which has an impact on autonomic nervous homeostasis resulting in glucose homeostasis and decreased fasting blood glucose; the mechanism of SaSo exercises can stimulate autonomic nervous homeostasis through the stimulation of the role of neuroception and the fusiform face area (FFA) receptors by responding to facial expressions of pregnant women, where FFA activation is made by one of the neurons called "face cells" in the temporal section [24] and (2) a mechanism through increased glucose uptake at the muscle and adipose cell levels. This description is supported by the previous research which showed that autonomic nervous balance can reduce blood glucose levels [7]. The theory of autonomic nerves is used to explain the mechanism of activation of the social nerve (vagus myelin) to create a relaxed and pleasant atmosphere during social nervous exercises. This theory is supported by the Polyvagal theory introduced by Porges 2001 [14]. The Polyvagal theory is a theory that emphasizes the phylogenetic origin of the brain structures that regulate social nerves. This theory states that the evolution of the mammalian autonomic nervous system provides a neurophysiological layer for emotional experience and affective processes that are the main components of social behavior. This theory provides a biological explanation of the role of social, emotional, and communication behavior [14].

The results of this study are supported by the previous studies stating that parasympathetic nerve stimulation can stimulate the pancreas and insulin through stimulation of acetylcholine receptors [9], [16]. These results are consistent with those observed by Shimazu et al. [25] who found electrical stimulation of the peripheral parasympathetic vagus nerves innervating the liver, which demonstrated parasympathetic control of the lateral hypothalamic nucleus through hepatic glycogenesis. One study conducted by Güemes and Georgiou [7] concluded that electrical stimulation of the parasympathetic nerves can reduce postprandial blood glucose levels so that glucose homeostasis occurs. Experimental studies in have shown that transcutaneous auricular vagus nerve stimulation (taVNS) significantly reduced the 2-h glucose tolerance and systolic blood pressure over time compared with sham taVNS [26]. taVNS bersifat antidiabetes dan antidepresif mungkin melalui peningkatan ekspresi reseptor insulin [27]. Research conducted by Alessio et al. [28] concluded that activation of the parasympathetic nerves during the absorption phase of food contributes significantly to the postprandial insulin secretory response.

Exercise training results in a sustained increase in insulin action on skeletal muscle in obese and insulin-resistant individuals. The molecular mechanism for increased glucose uptake with exercise training has been associated with increased expression and signaling activity of proteins as key involved in the regulation of glucose uptake and metabolism in skeletal muscles [29]. Evidence to support this study is shown in several observational studies that found pre-pregnancy 
exercise and exercise during pregnancy are associated with a decrease in insulin resistance, which has an impact on a reduced risk of developing GDM [29]. Yoga practice also helps in reducing blood glucose because it improves blood circulation and increases insulin sensitivity resulting in increased utilization of glucose by muscle cells [30]. Yoga diet and practice enhances the mind-body connection which results in physical and mental relaxation and reduction of physical and mental stress. Yoga practice has a positive effect on health through mechanisms of humoral activity and the nervous system [31]. Therefore, it is useful in lowering blood glucose [32].

Supported by the results of research by Davenport et al. [33], which states that the intervention of moderate-intensity exercise for 6 weeks in DMG patients can significantly reduce exogenous insulin requirements. In another study, it was shown that after a 6-week running exercise program could reduce fasting and 1-h postprandial blood glucose levels in DMG [29]. With the results of the previous studies concluded that women in the endurance exercise group for 3 days were in line with improving glucose control [34]. This was in the lower glucose levels (18 controls vs. $n=7$ exercise group). And stated that fasting blood glucose in the exercise intervention group was lower than the control group [35].

In contrast to the results of the study by Kokic et al. [35], concluded that there was no difference in fasting blood glucose between the two groups, namely, the exercise group that was regularly supervised plus brisk walking every day at least 30 min 2 times/week, and the control group only received antenatal care. GDM standards. In contrast, reported that the incidence of DMG was less in the exercise group than the control group, and there was no significant difference in fasting blood glucose in the exercise group and the control group [36]. Observed DMG women who were grouped into two exercise intervention groups and a control group, showing that there was no difference in fasting blood glucose levels in the exercise group and the control group [37].

\section{Conclusions}

A social nervous exercise program has a beneficial effect on insulin resistance (fasting blood glucose) levels in late pregnancy. It is expected that pregnant women can pay more attention to risk factors for GDM, which include the lack of physical activity. Increased physical activity with the social nervous exercise intervention is expected to control blood glucose homeostasis of GDM.

\section{References}

1. Daniel JA, Nzeribe E, Udoaku AA. Aerobic training impacts on blood cholesterol of women with gestational diabetes. Open $\mathrm{J}$ Obstet Gynecol. 2021;11:474-83.

2. Dipla K, Zafeiridis A, Mintziori G, Boutou AK, Goulis DG, Hackney AC. Exercise as a therapeutic intervention in gestational diabetes mellitus. Endocrines. 2021;2(2):65-78. https://doi.org/10.3390/endocrines2020007

PMid:33870263

3. Dirar AM, Doupis J. Gestational diabetes from A to Z. World J Diabetes. 2017;8(12):489-511. https://doi.org/10.4239/wjd. v8.i12.489 PMid:29290922

4. Amiri N, Metab D, Amiri FN, Sepidarkish M, Shirvani MA, Habibipour P. The effect of exercise on the prevention of gestational diabetes in obese and overweight pregnant women: A systematic review and metaanalysis. Diabetol Metab Syndr. 2019;11(1):1-14. https://doi.org/10.1186/s13098-019-0470-6

5. Koo BK, Lee JH, Kim J, Jang EJ, Lee $\mathrm{CH}$. Prevalence of gestational diabetes mellitus in Korea: A national health insurance database study. PLoS One. 2016;11(4):e0153107. https://doi.org/10.1371/journal.pone.0153107

PMid:27046149

6. Birmingham K, Gradinaru V, Anikeeva P, Grill WM, Pikov V, Mclaughlin B, et al. Bioelectronic medicines: A research roadmap. Nat Rev Drug Discov. 2014;13(6):399-400. https:// doi.org/10.1038/nrd4351

PMid:24875080

7. And AG, Georgiou P. Review of the role of the nervous system in glucose homoeostasis and future perspectives towards the management of diabetes. Bioelectron Med. 2018;4:9. https:// doi.org/10.1186/s42234-018-0009-4

PMid:32232085

8. Chandra R, Liddle RA. Recent advances in the regulation of pancreatic secretion. Curr Opin Gastroenterol. 2014;30(5):490-4. https://doi.org/10.1097/MOG.0000000000000099 PMid:25003603

9. Couck MD, Mravec B, Gidron Y. You may need the vagus nerve to understand pathophysiology and to treat diseases. Clin Sci (Lond). 2012;122(7):323-8. https://doi.org/10.1042/ CS20110299

PMid:22150254

10. Carnagarin R, Matthews VB, Herat LY, Ho JK, Schlaich MP. Autonomic regulation of glucose homeostasis: A specific role for sympathetic nervous system activation. Curr Diab Rep. 2018;18(11):107. https://doi.org/10.1007/s11892-018-1069-2 PMid:30232652

11. PorgesSW.The polyvagal theory:Phylogenetic substrates ofasocia nervous system. Int J Psychophysiol [Internet]. 2001;42(2):123-46. https://doi.org/10.1016/S0167-8760(01)00162-3. PMid:11587772

12. Porges SW. The polyvagal theory: New insights into adaptive reactions of the autonomic nervous system. Cleve Clin J Med. 2009;76 Suppl 2:S86-90. https://doi.org/10.3949/ccjm.76.s2.17 PMid: 19376991

13. Kaneto A, Miki E, Kosaka K. Effects of Vagal Stimulation on Glucagon and Insulin Secretion; 2015.

14. Porges SW. Comprehensive psychoneuroendocrinology polyvagal theory: A biobehavioral journey to sociality. Compr Psychoneuroendocrinol. 2021;7:100069. https://doi. org/10.1016/j.cpnec.2021.100069 
15. Sheen J, Wright JD, Goffman D, Kern-goldberger AR, Booker W, Ms ZS, et al. Maternal age and risk for adverse outcomes. Am J Obstet Gynecol. 2018;219(4):390.e1-15. https://doi.org/10.1016/j. ajog.2018.08.034

16. Braunthal S, Brateanu A. Hypertension in pregnancy: Pathophysiology and treatment. SAGE Open Med. 2019;7:2050312119843700. https://doi. org/10.1177/2050312119843700

\section{PMid:31007914}

17. Ramakrishnan U, Grant F, Goldenberg T, Zongrone A Martorell R. Effect of women's nutrition before and during early pregnancy on maternal and infant outcomes: A systematic review. Paediatr Perinat Epidemiol. 2012;26 Suppl 1:285-301. https://doi.org/10.1111/j.1365-3016.2012.01281.x PMid:22742616

18. Tian Y, Shen L, Wu J, Chen W, Yuan J, Yang H, et al. Parity and the risk of diabetes mellitus among Chinese women: A crosssectional evidence from the tongji-dongfeng cohort study. PLoS One. 2014;9(8):e104810. https://doi.org/10.1371/journal. pone. 0104810

PMid:25105792

19. Moosazadeh M, Asemi Z, Lankarani KB, Tabrizi R, Maharlouei N, Naghibzadeh-Tahami A, et al. Family history of diabetes and the risk of gestational diabetes mellitus in Iran : A systematic review and meta-analysis. Diabetes Metab Syndr. 2017;11 Suppl 1:S99-104. https://doi.org/10.1016/j.dsx.2016.12.016

PMid:28017634

20. Groof Z, Garashi G, Husain H, Owayed S, AlBader S, Mouhsen $\mathrm{H}$, et al. Prevalence, risk factors, and fetomaternal outcomes of gestational diabetes mellitus in kuwait: A crosssectional study. J Diabetes Res. 2019;2019:9136250. https:// doi.org/10.1155/2019/9136250

PMid:30944829

21. Erem C, Kuzu UB, Deger O, Can G. Prevalence of gestational diabetes mellitus and associated risk factors in Turkish women: The Trabzon GDM study. Arch Med Sci. 2015;11(4):724-35. https://doi.org/10.5114/aoms.2015.53291

PMid:26322083

22. Levy A, Wiznitzer A, Holcberg G, Mazor M, Sheiner E. Family history of diabetes mellitus as an independent risk factor for macrosomia and cesarean delivery. J Matern Fetal Neonatal Med. 2010;23(2):148-52. https://doi. org/10.3109/14767050903156650 PMid: 19637110

23. Flaa A, Aksnes TA, Kjeldsen SE, Eide I, Rostrup M. Increased sympathetic reactivity may predict insulin resistance: An 18-year follow-up study. Metabolism. 2008;57(10):1422-7. https://doi. org/10.1016/j.metabol.2008.05.012 PMid:18803948

24. Kanwisher N, Mcdermott J, Chun MM. The fusiform face area: A module in human extrastriate cortex specialized for face perception. J Neurosci. 1997;17(11):4302-11. https://doi. org/10.1523/JNEUROSCI.17-11-04302.1997 PMid:9151747

25. Shimazu T, Sudo M, Minokoshi $Y$, Takahashi A. Role of the hypothalamus in insulin-independent glucose uptake in peripheral tissues. Brain Res Bull. 1991;27(3-4):501-4. https:// doi.org/10.1016/0361-9230(91)90149-E.

PMid:1959052

26. Huang $F$, Dong J, Kong J, Wang $H$, Meng $H$, Spaeth RB, et al. Effect of transcutaneous auricular vagus nerve stimulation on impaired glucose tolerance: A pilot randomized study. BMC Complement Altern Med. 2014;14:203. https://doi. org/10.1186/1472-6882-14-203 PMid:24968966

27. Li S, Zhai X, Rong P, Mccabe MF, Wang X, Zhao J, et al. Therapeutic effect of vagus nerve stimulation on depressivelike behavior, hyperglycemia and insulin receptor expression in zucker fatty rats. PLoS One. 2014;9(11):e112066. https://doi. org/10.1371/journal.pone. 0112066

PMid:25365428

28. Alessio DA, Kieffer TJ, Taborsky GJ, Havel PJ. Activation of the parasympathetic nervous system is necessary for normal mealinduced insulin secretion in rhesus macaques. J Clin Endocrinol Metab. 2001;86(3):1253-9. https://doi.org/10.1210/jcem.86.3.7367 PMid: 11238517

29. Wang $\mathrm{C}$, Janese $\mathrm{K}$, Yang $\mathrm{H}$. ScienceDirect Exercise and its role in gestational diabetes mellitus. Chronic Dis Transl Med. 2016;2(4):208-14. https://doi.org/10.1016/j.cdtm.2016.11.006 PMid:29063044

30. Balaji PA, Varne SR. Physiological effects of yoga asanas and pranayama on metabolic parameters, maternal, and fetal outcome in gestational diabetes. J Physiol Pharm Pharmacol. 2017;7(7):724-8.

31. Kuntsevich V, Bushell WC, Theise ND. Mechanisms of yogic practices in health, aging, and disease. Mt Sinai J Med. 2010;77(5):559-69. https://doi.org/10.1002/msj.20214 PMid:20960557

32. Youngwanichsetha $S$, Phumdoung $S$, Ingkathawornwong $T$. The effects of mindfulness eating and yoga exercise on blood sugar levels of pregnant women with gestational diabetes mellitus. Appl Nurs Res. 2014;27(4):227-30. https://doi.org/10.1016/j. apnr.2014.02.002 PMid:24629718

33. Davenport MH, Mottola MF, McManus R, Gratton R. A walking intervention improves capillary glucose control in women with gestational diabetes mellitus: A pilot study. Appl Physiol Nutr Metab. 2008;33(3):511-7. https://doi.org/10.1139/H08-018 PMid:18461104

34. de Barros MC, Lopes MA, Francisco RP, Sapienza AD, Zugaib M. Resistance exercise and glycemic control in women with gestational diabetes mellitus. Am J Obstet Gynecol. 2010;203(6):556.e1-6. https://doi.org/10.1016/j. ajog.2010.07.015

PMid:20864072

35. Kokic IS, Ivanisevic M, Biolo G, Simunic B, Kokic T, Pisot R. Combination of a structured aerobic and resistance exercise improves glycaemic control in pregnant women diagnosed with gestational diabetes mellitus. A randomised controlled trial. Women and birth. 2018;31(4):e232-8. https://doi.org/10.1016/j. wombi.2017.10.004

PMid: 29055674

36. Garnæs KK, Mørkved S, Salvesen $\varnothing$, Moholdt T. Exercise training and weight gain in obese pregnant women: A randomized controlled trial (ETIP Trial). PLoS Med. 2016;13(7):e1002079. https://doi.org/10.1371/journal.pmed.1002079 PMid:27459375

37. Avery MD, Leon AS, Kopher RA. Effects of a partially homebased exercise program for women with gestational diabetes. Obstet Gynecol. 1997;89(1):10-5. https://doi.org/10.1016/ s0029-7844(97)84256-1

PMid:8990428 